\title{
MEASURING OF BRAKING DISTANCES OF FIREFIGHTING TRUCKS
}

Ladislav Jánošík ${ }^{1}$, Ivana Jánošíková², Jiř́i Kuczaj’’, Pavel Poledňák ${ }^{1}$, Izabela Šudrychová1, Martin Tomášek ${ }^{4}$, Josef Vlček ${ }^{5}$

${ }^{1}$ Faculty of Safety Engineering, VSB - Technical University of Ostrava, Ostrava, Czech Republic

${ }^{2}$ Faculty of Economics, VSB - Technical University of Ostrava, Ostrava, Czech Republic

${ }^{3}$ Fire Rescue Services of Moravian-Silesian Region, Ostrava, Czech Republic

${ }^{4}$ Fire Rescue Services of Karlovy Vary Region, Karlovy Vary, Czech Republic

${ }^{5}$ Fire Rescue Services of Zlin Region, Zlin, Czech Republic

*E-mail of corresponding author: ladislav.janosik@vsb.cz

\section{Resume}

The paper addresses the driving dynamics of emergency fire trucks. It focuses on the issues of braking, measuring real braking distances and calculating adhesion coefficients. It presents the results of measuring the real braking distances for firefighting vehicles - type water tenders. Measurements were taken on dry asphalt and depending on the vehicle's speed of travel. Experiments were conducted on five types of firefighting vehicles. The results of measurements are mainly used by fire protection units to the drivers' self-education to improve safety when driving to intervene.

Available online: https://doi.org/10.26552/com.C.2022.2.F1-F13

\section{Article info}

Received 11 January 2021

Accepted 1 October 2021

Online 2 December 2021

\section{Keywords:}

braking distance

braking deceleration

braking time

adhesion coefficient

firefighting vehicles

\section{Introduction}

The paper follows a previous publication by the authors [1]. Braking on different types of road surface in a straight line or on a curve is one of the basic driving skills a driver needs to be able to handle in a critical situation on a road. This is doubly true for fire truck drivers. Their primary task is to ensure the safe and rapid transport of the fire protection unit to the emergency site. The speed of the fire truck should be adjusted to stop safely in any critical situation where the avoidance manoeuvre cannot be performed. An analysis of accident statistics for the years 2011 to 2016 [2] showed that speeding was the cause of 35 road accidents $(19 \%)$ involving water tender vehicles when driving to intervene. These accidents accounted for up to $89 \%$ of the total damage to firefighting vehicles (CZK 36.9 million = 1.45 million EUR) for the analysed period [2] . This year, co-authors have extended the analysis to 2019 [3]. A total of 318 culpable traffic accidents of vehicles of water tender type were analysed for the period 2011 to 2019. The most common cause was incorrect avoidance 115 traffic accidents (36 \%). The inappropriate speed was the cause for 54 traffic accidents (17\%). However, the damage to water tender-type vehicles was 51.8 million $\mathrm{CZK}=2,04$ million EUR $(71 \%)$. These facts were the reason why the co-authors address repeatedly the basic driving parameter of firefighting trucks, i.e. braking distance and its changes in different driving conditions. This research focuses on the specific type of vehicles, the type of tyres, testing on dry asphalt surface and air temperatures above freezing. Measurements were taken on firefighting vehicles dislocated at Zlin, Hlucin and Marianske Lazne fire stations. The test runs took place on the paved asphalt surface of two airfields and one training polygon.

\section{$2 \quad$ Firefighting trucks}

Five firefighting trucks were used for the measurement. Basic information about the vehicles tested is given in Table 1.

The first tested fire truck is a MAN TGM 18.340 $4 x 4 B B$, it has a CAS 20/4000/300-S2Z fire mark and is placed as the first car at a fire station (FS) in Zlin. It is a heavy-weight emergency fire truck capable of operating on and partially off all the roads. It is basically equipped. It has a pump with a nominal flow rate 2,000 l.min ${ }^{-1}$. The water tank has a capacity of 4,000 litres and the foam tank has 300 litres. The length of the vehicle is $8,500 \mathrm{~mm}$, width $2,550 \mathrm{~mm}$, height $3,200 \mathrm{~mm}$. The total 
Table 1 List of tested vehicles

\begin{tabular}{llll}
\hline Vehicle & Fire signs & Registration mark & Dislocation \\
\hline MAN TGM 18.340 4x4 & CAS 20/4000/300-S2Z & 4 Z2 4898 & FS Zlin \\
Renault Midlum 270.14 P 4x4 & CAS 24/2500/250-M2T & 2 Z7 8478 & FS Zlin \\
Scania P 480 CB 4x4 EHZ & CAS 20/4000/240-S2T & 3 K5 1139 & FS Marianske Lazne \\
TATRA T815-2 TerrNo1 4x4.2 & CAS 20/4000/240-S2T & 8 T8 6180 & FS Hlucin \\
MAN TGM 18.280 4x4 & CAS 24/5000-S2R & 4 T3 4949 & FS Hlucin \\
\hline
\end{tabular}

mass of the vehicle is $16,500 \mathrm{~kg}$. The drum brakes are on both axles. The car is equipped with a two-ring air braking system with an ABS. Before the measuring, the car was fitted with Continental HSC1 M+S 295/80 $\mathrm{R} 22.5$ steer cordless radial tyres on the front axle and with Continental HDC1 tyres M+S 295/80 R 22.5 on the rear axle. The tyres had an identical tread depth of $12 \mathrm{~mm}$ and were inflated with a pressure of $600 \mathrm{kPa}$. Front tyres were produced in week 10 of 2016 and rear tyres in week 20 in 2010.

The second measured truck is a Renault MIDLUM $270.144 x 4$, it has a CAS 24/2500/25 M2T fire mark and is deployed as the second-exit truck at a fire station in Zlin. It is a medium-weight emergency fire truck, capable of operating on and partly off all the roads. The vehicle is of a technical design. It is equipped with a pump with a nominal flow rate $2,4001 . \mathrm{min}^{-1}$. The volume of the water tank is 2,5001 , the volume of the foam tank is 2501. The vehicle chassis is the two-axle with continuous propulsion of both axles. The length of the vehicle is $7,920 \mathrm{~mm}$, width $2,500 \mathrm{~mm}$, height $3,290 \mathrm{~mm}$. The total mass of the vehicle is $14,000 \mathrm{~kg}$. The car is equipped with a two-ring compressed air system. The disc brakes are on both axles. The vehicle has an ABS system only. The car was fitted with steer cordless radial Michelin XZY $10 \mathrm{R}$ 22.5 144/142 K tyres on the front axle. The Bridgestone M $71610 \mathrm{R} 22.5$ tyres were on the rear axle with dual mounting. The tyres were inflated with a pressure of 600 $\mathrm{kPa}$. All tyres were manufactured in the 1 st week of 2015 and had an identical depth of tread of $12 \mathrm{~mm}$.

The third tested fire vehicle is a Scania $P 480 C B$ $4 \times 4$ EHZ with fire mark CAS 20/4000/240-S2T located at the Marianske Lazne fire station. It is a heavy weight fire engine. It has a two-axle chassis with a continuous frame, capable of operating on and partially off all the roads. The vehicle is of a technical design; it has a permanent rear axle drive fitted with a differential lock. It also has an attributable front axle drive, also fitted with a differential lock. The length of the vehicle is $8,360 \mathrm{~mm}$, width $2,550 \mathrm{~mm}$, height $3,050 \mathrm{~mm}$. The water tank has a capacity of 4,000 litres and the foam tank has 240 litres. The operating weight is $12,730 \mathrm{~kg}$ and the total weight is $18,000 \mathrm{~kg}$. The vehicle is equipped with a tworing compressed air system. The drum brakes are on both axles. The vehicle has a speed bump, ABS and ASR. The vehicle was fitted with Continental HSW2 Winter $\mathrm{M}+\mathrm{S}$ 315/80 R22.5 steer tubeless radial tyres on the front axle, during the experimental measurement. On the rear twin-mounted axle were tubeless Continental HDC1 315/80 R 22.5 radial tyres. The tyres on the front axle were inflated to $750 \mathrm{kPa}$ and on the rear axle to 650 $\mathrm{kPa}$. The tyres on the front axle had a DOT code of 0618 during the experimental measurement (manufactured at week 6 of 2018) and a DOT code of 0518 on the rear axle (manufactured at week 5 of 2018). The tyres on the front axle had an average tread depth of $12.3 \mathrm{~mm}$, the tyres on the rear inner axle $16.7 \mathrm{~mm}$ and on the outer rear axle an average tread depth of $16.9 \mathrm{~mm}$.

The fourth tested firefighting truck TATRA T815-2 TerrNo1 $4 x 4.2$ has a CAS 20/4000/240-S2T fire mark and is located at a fire station in Hlucin. The mark of the chassis is T815-231R55/411. It is a mixed-class twoaxle chassis with a mountable front-axle drive. Both axles are fitted with a differential lock. Vehicle length is $7,825 \mathrm{~mm}$, width $2,550 \mathrm{~mm}$, height $3,150 \mathrm{~mm}$. The water tank has a capacity of 4,000 litres and the foam tank has 240 litres. The total mass of the vehicle is $18,000 \mathrm{~kg}$. The car is equipped with a two-ring compressed air system. The drum brakes are on both axles. The vehicle has an ABS system only. The car was fitted with steer tubeless radial Michelin Cold 385/65 R 22.5 tyres on the front axle. On the rear twin-mounted axle were the tubeless all-year-round radial tyres of the brand Barum Road Drive 315/80 R 22.5. The front tyres were inflated with a pressure of $800 \mathrm{kPa}$, the rear ones $700 \mathrm{kPa}$ [3]. The tyres had a DOT code of 2614 (manufactured in week 26 of 2014) and a tread depth of $12 \mathrm{~mm}$.

The fifth tested firefighting water tender vehicle is a MAN TGM 18.280 4x4 with fire mark CAS 20/5000 S2R, which is also dislocated at the fire station in Hlucin, where it is used by the local volunteer fire brigade unit. The chassis and cab made by MAN, the superstructure was manufactured by Kobit THZ. The car is structurally designed to operate on both paved and unpaved roads, with the ability to drive both axles. The length of the vehicle is $8,700 \mathrm{~mm}$, wheelbase $4,200 \mathrm{~mm}$, width $2,550 \mathrm{~mm}$, height $3,350 \mathrm{~mm}$. The water tank has a capacity of 5,000 litres. The vehicle has no foam tank. Its absence is replaced by cartouches. The total weight is $18,000 \mathrm{~kg}$, so the vehicle belongs to a heavy weight class with an off-road chassis. The drum brakes are on both axles. The front axle is fitted with tubeless Continental HDR 11 R22.5 radial tyres inflated to a pressure of $830 \mathrm{kPa}$. The double-mounted rear axle is fitted with tubeless Continental HDR 295/80 R22.5 radial tyres inflated to a pressure of $830 \mathrm{kPa}$. 


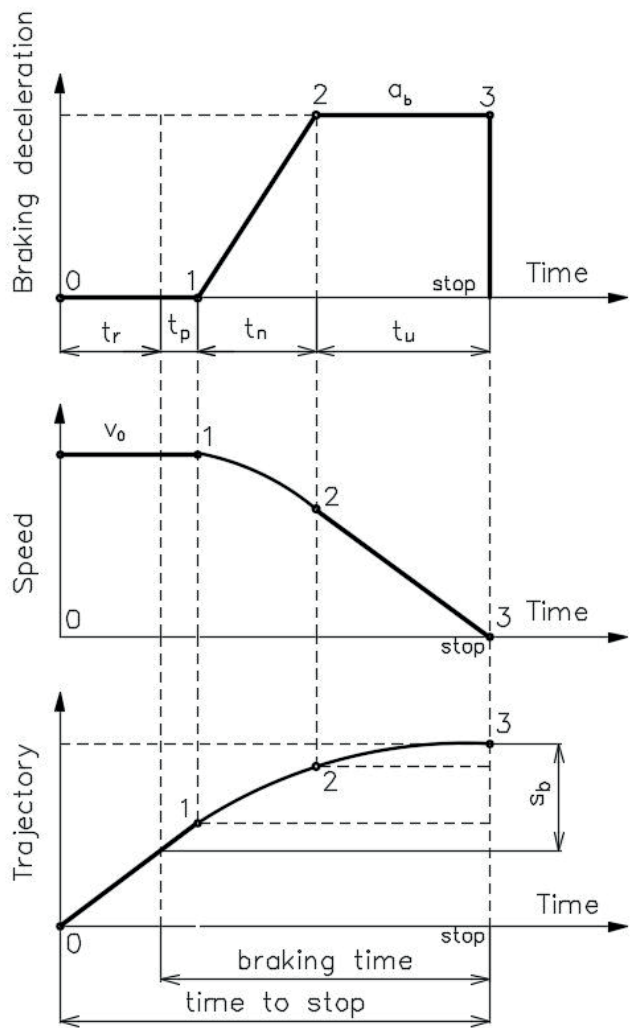

Figure 1 Course of the braking process

\section{$3 \quad$ Measuring instruments}

As with the previous measurement in 2018, the Performance Box made by Racelogic Ltd, Buckingham, England, was used to measure driving characteristics. A detailed description of the device is given on the manufacturer's website [4]. The apparatus is designed to detect the real-time absolute positioning of a vehicle. The instrument then calculates number of variables, such as the trajectory, the vehicle speed and acceleration. The frequency of the entries is $10 \mathrm{~Hz}$. Its accuracy is assured by determining the vehicle's position in real time by using signals from satellite systems GPS and GLONASS. An accuracy of $0.2 \mathrm{~km} / \mathrm{h}$ at a resolution of $0.01 \mathrm{~km} / \mathrm{h}$ is given for speed measurements. The accuracy of $0.05 \%$ (less than $0.5 \mathrm{~m}$ per $\mathrm{km}$ ) and resolution of $10 \mathrm{~mm}$ is for track measurement. The accuracy and resolution of the time recording is determined by the frequency of the device, i.e. $0.1 \mathrm{~s}$. The change in speed, braking distance and braking deceleration of the vehicle were assessed using that device. The Performance box was equipped with an SD card to store the recorded data, which was then transferred to the computer and further processed in VBOX Test Suite, version 1.7.55.2453.

\section{Theoretical basis of the braking process}

The theoretical course of the braking process can be depicted on three graphs (see Figure 1) that describe variations in speed, path, and acceleration over time [5]. The necessary variables are calculated then in the following Equations (1) to (3). For the calculation needs, the driver's response time $t_{r}$ was not included. Within experiments, the driver knows the moment of braking. He only keeps a constant speed until the start of braking on the test path is indicated.

The braking distance $s_{b}$ is calculated according the equation:

$s_{b}=v_{0} \cdot t_{p r}+\frac{1}{2} \cdot \frac{v_{0}^{2}}{\left|a_{b}\right|}$.

The initial speed $v_{0}$ is the speed at which the vehicle was moving before started braking. The preparation time $t_{p r}$ is characterized by the delay time $t_{p}$ and the reaction time $t_{n}$. The delay time is the time between the moment the brake pedal is tread on and the moment when the brake system starts to operate, i.e. when the brake lining abuts against the brake pad. The reaction time is the time before the brakes start to work fully. The preparation time is calculated according to the equation:

$t_{p r}=t_{p}+\frac{t_{n}}{2}$.

According to [6], the variables' values are usually $t_{p}=0.05-0.15 \mathrm{~s}, t_{n}=0.03-0.15 \mathrm{~s}$. The average values, used for the assessment of traffic accidents, are given $t_{p}$ $=0.1 \mathrm{~s}$ and $t_{n}=0.2 \mathrm{~s}$ [5]. Theoretically, one can calculate the braking deceleration $a_{b}$ according to the equation: 


$$
\left|a_{b}\right|=g \cdot \mu \text {. }
$$

The coefficient of adhesion $\mu$ can be taken from the literature for a theoretical calculation, e.g. [6]. This basic theory has served us to calculate the required theoretical braking distance for the safe conduct of the experiments before the measurements begin.

\section{Methods}

Experimental measurements of braking distances took place at selected locations in each region according to the location of vehicles at fire stations. The conditions for the experiment were a dry surface of communication and full tanks of extinguishers. Braking time and braking distance measurements were scheduled for initial speeds of $30,40,50,60$ and $70 \mathrm{~km} \cdot \mathrm{h}^{-1}$. The experiments began at the lowest speed and repeated up to $70 \mathrm{~km} \cdot \mathrm{h}^{-1}$.

The measurement of the trucks MAN TGM 4x4 (FS Zlin) and Renault Midlum 270.14 P 4x4 (FS Zlin) took place at Slusovice Airport, s. r. o. - Bila Hlina, Neubuz 138, 76315 Slusovice, on October 18, 2019. The runway of the airport is 400 meters long. Measurement started at 1 p.m. The air temperature was $23^{\circ} \mathrm{C}$. The distance the vehicle has travelled from the point of dislocation to the test track was $13 \mathrm{~km}$. An example of the position recording of the MAN TGM $4 \times 4$ vehicle on the site of Slusovice Airport into a map base when evaluating a group of experiments in the VBOX Test Suite software is shown in Figure 2.

The braking distance of the vehicle Scania P 480 CB 4x4 EHZ was measured at Cheb airport, Horni Dvory 19, 35002 Cheb, on November 1, 2019. The runway of the airport is 1,400 meter long. The measurement started at 3:30 p.m. The air temperature was $6{ }^{\circ} \mathrm{C}$. The vehicle travelled $5 \mathrm{~km}$ distance from the point of its dislocation to the test site. The trajectories of the measured runs of the truck Scania P 480 CB 4x4 EHZ at Cheb Airport are shown on Figure 3.

The braking distances of the trucks Tatra 815-2 $4 \times 4$ (FS Hlucin) and MAN TGM 4x4 (FS Hlucin) were measured at the LIBROS Safe Ride Centre training polygon in Ostrava, Palackeho 1114, on November 11, 2019 and December 2, 2019. The measurement in November began at 9:00 a.m. The air temperature was $6{ }^{\circ} \mathrm{C}$ in the morning and had risen to $13{ }^{\circ} \mathrm{C}$ at $12: 00$ a.m. Measurement in December began at 8:00 a.m. The air temperature was $1^{\circ} \mathrm{C}$ in the morning and had risen to $11{ }^{\circ} \mathrm{C}$ at 2:00 p.m. The length of the polygon is 320 metres; the distance the vehicle has travelled from the point of dislocation to the test track was $11 \mathrm{~km}$. Figure 4

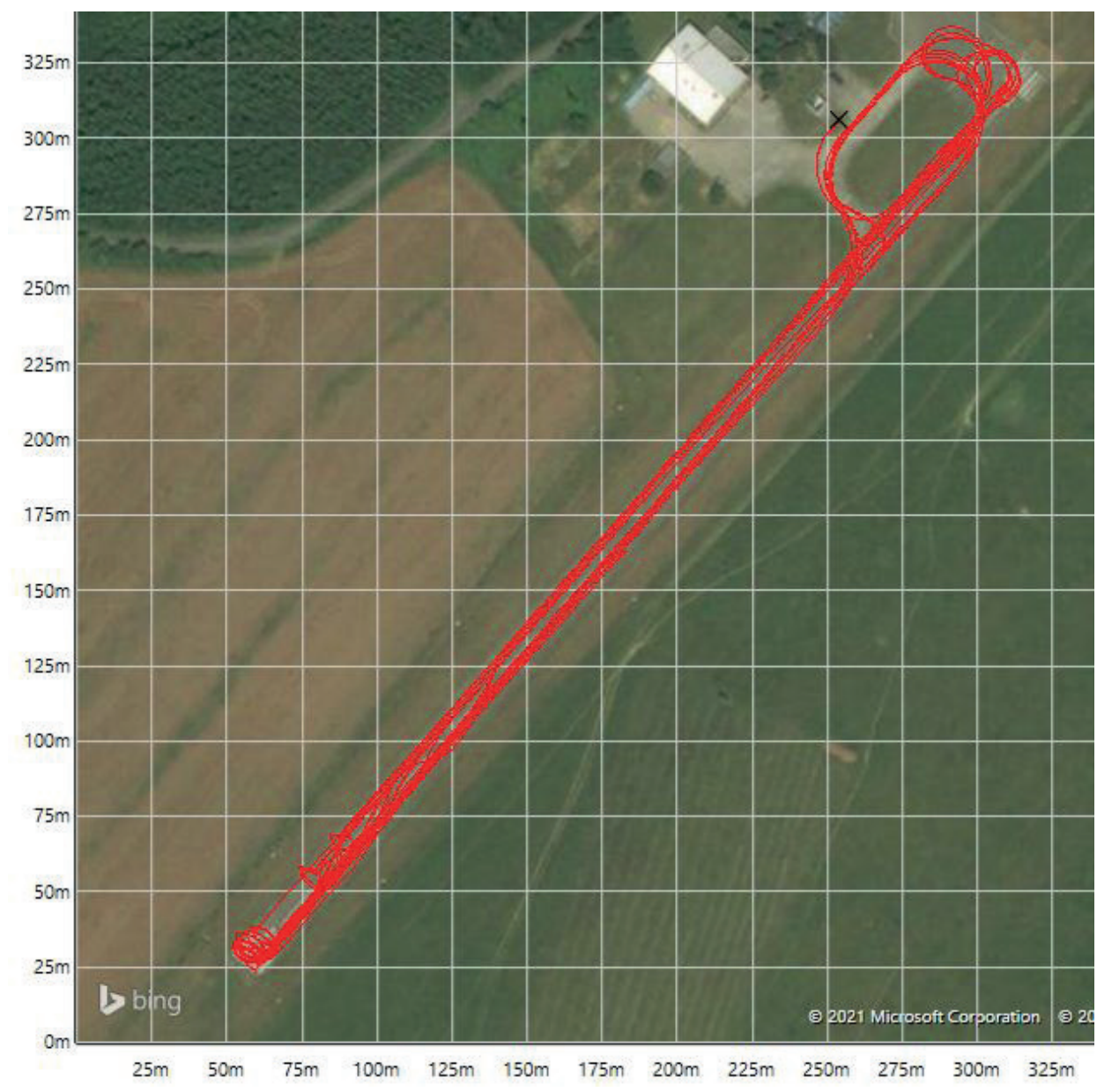

Figure 2 Trajectory of metered runs at Slusovice airport [7] 


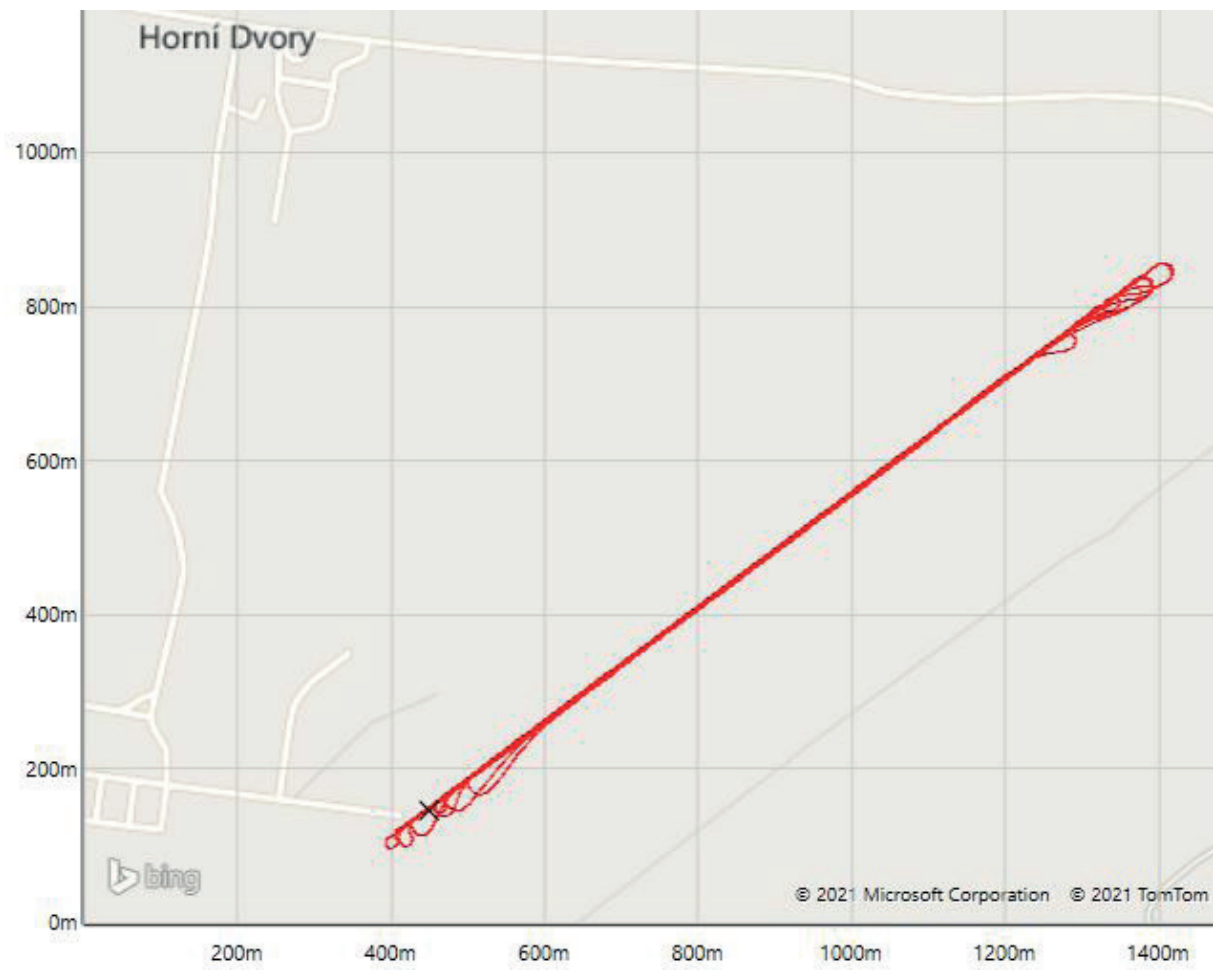

Figure 3 Trajectory of metered runs at Cheb airport [7]

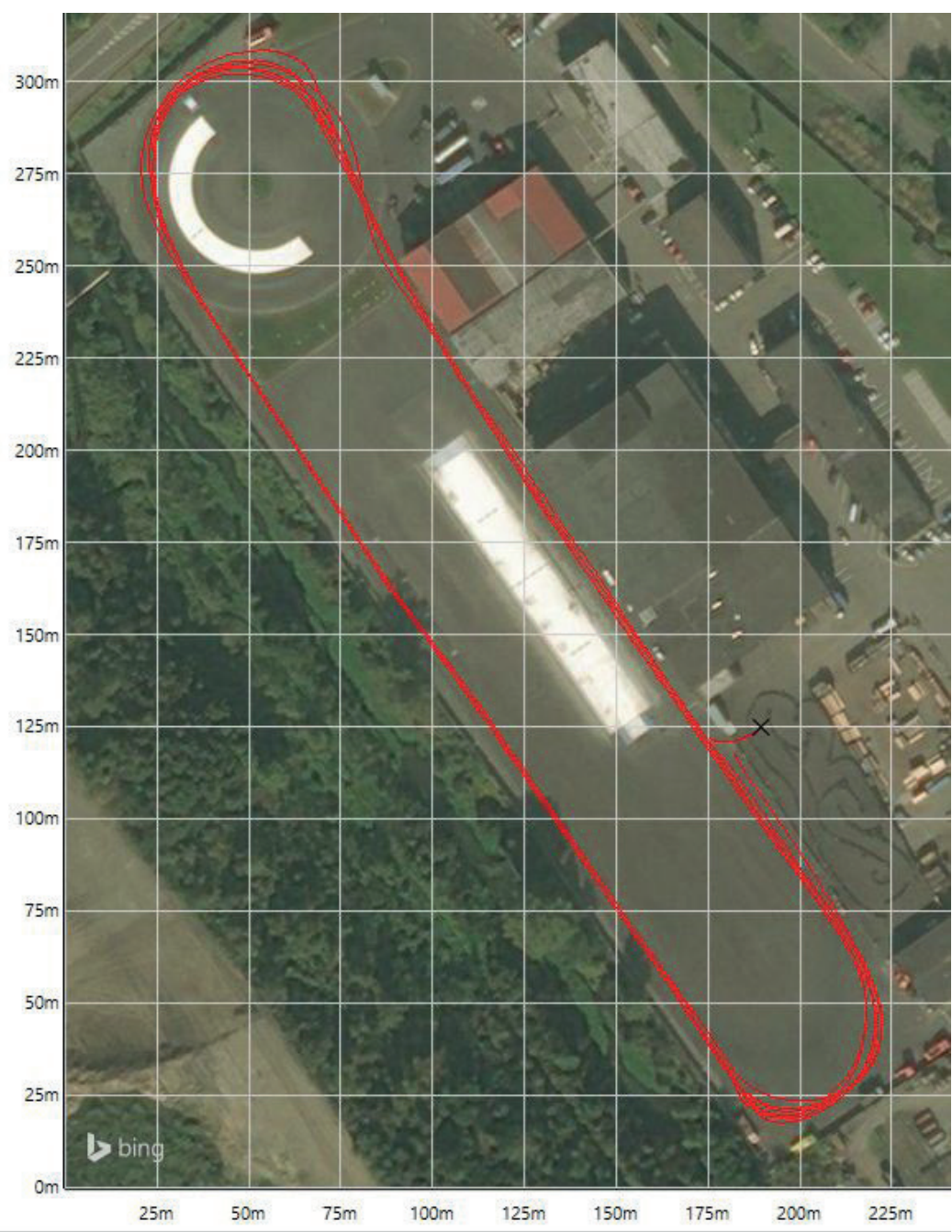

Figure 4 Trajectory of metered runs on the LIBROS polygon in Ostrava [7] 


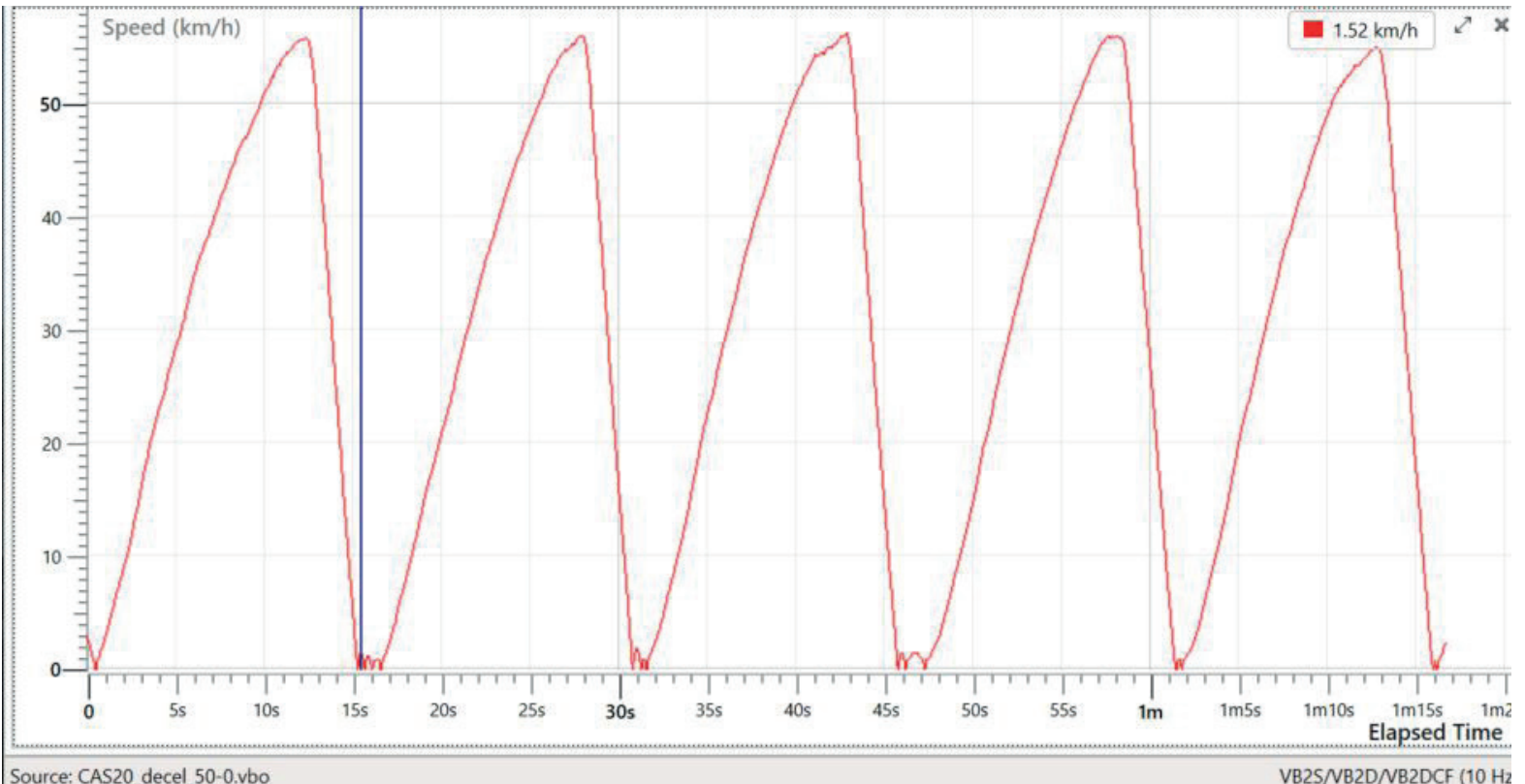

Figure 5 Record of speed versus time for CAS 20 SCANIA vehicle

shows a record of the position of a MAN TGM $4 \times 4$ vehicle measured on the LIBROS polygon in Ostrava. The cross here indicates the starting position of the truck before the first run.

To set the real adhesion coefficients $\mu$ according to Equation (3), the braking distance of a vehicle $s_{b}$ had to be determined from the experimental measurements during their subsequent processing. The braking distance is given by the point of change (decrease) of the initial $v_{0}$ speed, at which the driver began to brake the car, up to the stopping point of the vehicle. The braking time was also found out from the graphs.

The procedure for each experiment was as follows.
A Performance Box device was placed in the car. Once connected to the power supply, the instrument was automatically activated and started searching for a link to the navigation satellite for setting the position. After the connection was established, the device was switched to the current vehicle speed display mode. This allowed the driver to compare the speed of his driving with the speedometer in the vehicle. Then, the test runs could begin. The driver drove the vehicle along a straight section of the test track and began accelerating to the agreed initial speed $v_{0}$. After achieving and stabilizing this speed, the driver began to apply the maximum brakes. These experiments were conducted for each

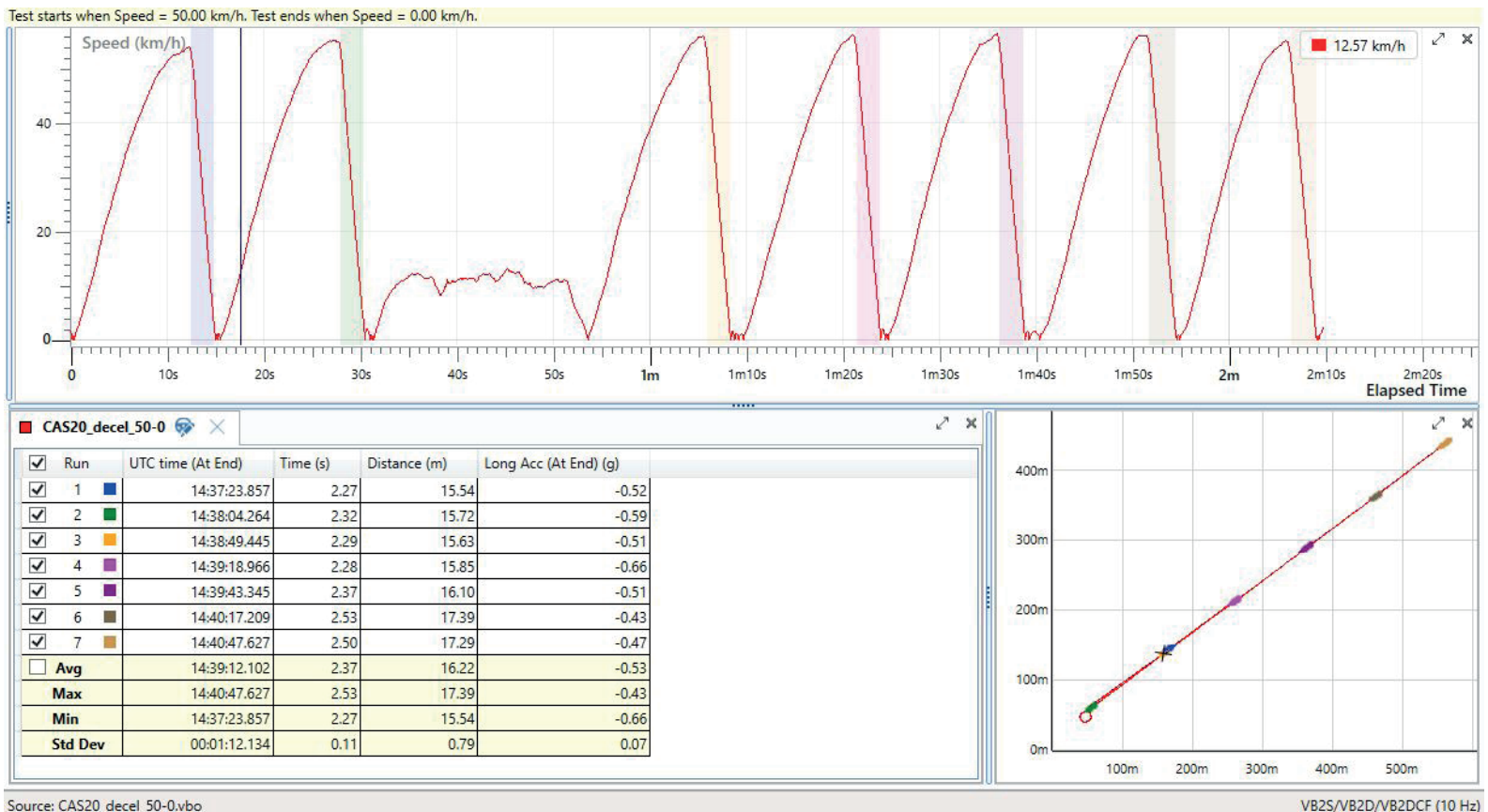

Figure 6 Demonstration of the vehicle CAS 20 SCANIA braking assessment for initial speed $v_{0}=50 \mathrm{~km} . \mathrm{h}^{-1}$ 
of the 5 tested trucks. It has been determined that 5 experimental runs should be carried out. In the situation that the necessary speed has not been achieved while driving, one or two additional measurements were taken. In the results afterwards, the worst or unusable measurements were excluded from evaluation (if the necessary speed was not reached). That was particularly the case of the shortest track at the LIBROS polygon. Due to insufficient runway for starting the vehicle to the agreed speed and for the safe stopping, the braking distance of the trucks MAN TGM and TATRA T815-2 from Hlucin fire station for the speed $70 \mathrm{~km} . \mathrm{h}^{-1}$ was not tested there.

\section{Results}

The presentation of the results of each experiment is summarised in the following. The processed record of the speed, in terms of the running time of the truck CAS 20 Scania P $480 \mathrm{CB} 4 \mathrm{x} 4 \mathrm{EHZ}$, when testing the braking time and stopping distance for an initial speed $50 \mathrm{~km} . \mathrm{h}^{-1}$, is shown in Figure 5 . The record registers the progress of the measurements of each run in the relative time of the telemetry.

Figure 6 shows the processing of the obtained data from the braking test of all 7 runs from the above record.
The software workspace is divided into three parts. At the top right is a graph showing the stopping distance from the initial speed $v_{0}=50 \mathrm{~km} \cdot \mathrm{h}^{-1}$ until the vehicle stopped. At the bottom left is a table that summarizes the measured passing distance as a function of time. The lower right-hand image shows the path of the vehicle when measuring the braking distance. The resulting values were calculated by VBOX Test Suite software under the condition that the initial speed was $v_{0}=50$ $\mathrm{km} \cdot \mathrm{h}^{-1}$ and the end speed was zero, when evaluating all 7 measurements.

Table 2 shows the calculated result values of braking time, braking distance and braking deceleration (in times of gravitational acceleration), including their diameters and deviations. In the last column, a conversion of braking deceleration $a_{b}$ to the units of the SI system is added.

The full results of the measured braking distances $s_{b}(\mathrm{~m})$, including the arithmetic averages and deviations, are given in Tables 3 to 7 .

Tables 8 to 12 summarise the resulting average values of the measured variables.

The results of measured braking distance in relation to the initial speed are summarized in Figure 7. The chart legend shows the individual vehicles and their dislocation as well as the tyre types used on the front axle of each truck.

Table 2 Braking distance measurement results for the truck CAS 20 SCANIA for initial speed $v_{0}=50 \mathrm{~km} . \mathrm{h}^{-1}$

\begin{tabular}{cccccc}
\hline \multirow{2}{*}{ Run } & UTC time & Time $(\mathrm{s})$ & Distance $(\mathrm{m})$ & $\begin{array}{c}\text { Long Acc (At End) } \\
(\mathrm{g})\end{array}$ & $\left|\mathrm{a}_{\mathrm{b}}\right|\left(\mathrm{m} . \mathrm{s}^{-2}\right)$ \\
\hline 1 & $14: 37: 23.857$ & 2.27 & 15.54 & -0.52 & 5.10 \\
2 & $14: 38: 04.264$ & 2.32 & 15.72 & -0.59 & 5.79 \\
3 & $14: 38: 49.445$ & 2.29 & 15.63 & -0.51 & 5.00 \\
4 & $14: 39: 18.966$ & 2.28 & 15.85 & -0.66 & 6.47 \\
5 & $14: 39: 43.345$ & 2.37 & 16.10 & -0.51 & 5.00 \\
6 & $14: 40: 17.209$ & 2.53 & 17.39 & -0.43 & 4.22 \\
7 & $14: 40: 47.627$ & 2.50 & 17.29 & -0.47 & 4.61 \\
\hline Avg & & 2.37 & 16.22 & -0.53 & 5.20 \\
\hline Max & & 2.53 & 17.39 & -0.43 & 6.47 \\
Min & & 2.27 & 15.54 & -0.66 & 4.22 \\
Std Dev & & 0.11 & 0.79 & 0.07 & 0.82 \\
\hline
\end{tabular}

Table 3 Braking distance measurements for truck CAS 20 MAN (FS Zlin)

\begin{tabular}{|c|c|c|c|c|c|}
\hline $\mathrm{v}_{0}(\mathrm{~km} / \mathrm{h})$ & 30 & 40 & 50 & 60 & 70 \\
\hline 1 & 5.31 & 9.51 & 14.31 & 21.17 & 32.01 \\
\hline 2 & 5.31 & 9.80 & 14.70 & 19.57 & 32.47 \\
\hline 3 & 5.02 & 10.14 & 14.99 & 21.15 & 33.70 \\
\hline 4 & 5.05 & 10.26 & 14.65 & 20.15 & 37.32 \\
\hline 5 & 5.68 & - & 15.82 & - & 36.13 \\
\hline Avg & 5.27 & 9.93 & 14.90 & 20.51 & 34.33 \\
\hline Max & 5.68 & 10.26 & 15.82 & 21.17 & 37.32 \\
\hline Min & 5.02 & 9.51 & 14.31 & 19.57 & 32.01 \\
\hline Std Dev & 0.26 & 0.34 & 0.57 & 0.79 & 2.31 \\
\hline
\end{tabular}


Table 4 Braking distance measurements for truck CAS 20 Renault (FS Zlin)

\begin{tabular}{cccccc}
\hline $\mathrm{v}_{0}(\mathrm{~km} / \mathrm{h})$ & 30 & 40 & 50 & 60 & 30 \\
\hline 1 & 5.90 & 11.11 & - & 22.12 & 30.93 \\
2 & 5.61 & 9.42 & 13.54 & 21.37 & 32.21 \\
3 & 5.29 & 9.57 & 13.81 & 22.93 & 33.14 \\
4 & 6.16 & 9.54 & 15.95 & 21.82 & 34.11 \\
5 & 6.04 & 10.69 & 15.32 & 21.85 & 33.52 \\
\hline Avg & 5.80 & 10.06 & 14.65 & 22.02 & 32.78 \\
\hline Max & 6.16 & 11.11 & 15.95 & 22.93 & 34.11 \\
Min & 5.29 & 9.42 & 13.54 & 21.37 & 30.93 \\
Std Dev & 0.35 & 0.78 & 1.17 & 0.58 & 1.24 \\
\hline
\end{tabular}

Table 5 Braking distance measurements for truck CAS 20 SCANIA (FS Marianske Lazne)

\begin{tabular}{|c|c|c|c|c|c|}
\hline $\mathrm{v}_{0}(\mathrm{~km} / \mathrm{h})$ & 30 & 40 & 50 & 60 & 70 \\
\hline 1 & 5.05 & 9.3 & 15.54 & 27.54 & 31.24 \\
\hline 2 & 5.27 & 9.46 & 15.72 & 23.97 & 33.02 \\
\hline 3 & 4.79 & 9.92 & 15.63 & 22.52 & 33.7 \\
\hline 4 & 5.06 & 9.52 & 15.85 & 21.22 & 32.31 \\
\hline 5 & 5.06 & 8.97 & 16.10 & 24.39 & 33.91 \\
\hline 6 & 5.44 & 10.11 & 17.39 & - & - \\
\hline 7 & - & - & 17.29 & 23.69 & 34.8 \\
\hline Avg & 5.11 & 9.55 & 16.22 & 23.89 & 33.16 \\
\hline Max & 5.44 & 10.11 & 17.39 & 27.54 & 34.8 \\
\hline Min & 4.79 & 8.97 & 15.54 & 21.22 & 31.24 \\
\hline Std Dev & 0.22 & 0.42 & 0.79 & 2.13 & 1.26 \\
\hline
\end{tabular}

Table 6 Braking distance measurements for truck CAS 20 TATRA (FS Hlucin)

\begin{tabular}{ccccc}
\hline $\mathrm{v}_{0}(\mathrm{~km} / \mathrm{h})$ & 30 & 40 & 50 & 60 \\
\hline 1 & 5.90 & 11.20 & 15.79 & 23.30 \\
2 & 6.18 & 9.31 & 18.62 & 23.94 \\
3 & 5.80 & 10.10 & 17.59 & 25.39 \\
4 & 6.80 & 9.85 & 14.75 & 25.69 \\
5 & 5.87 & 9.95 & 16.88 & 26.17 \\
6 & 5.41 & 10.67 & 15.65 & 25.49 \\
\hline Avg & 5.99 & 10.18 & 16.55 & 25.00 \\
\hline Max & 6.80 & 11.20 & 18.62 & 26.17 \\
Min & 5.41 & 9.31 & 14.75 & 23.30 \\
\hline
\end{tabular}

Table 7 Braking distance measurements for truck CAS 24 MAN (FS Hlucin)

\begin{tabular}{ccccc}
\hline$v_{0}(\mathrm{~km} / \mathrm{h})$ & 30 & 40 & 50 & 60 \\
\hline 1 & 5.85 & 10.00 & 16.05 & 20.24 \\
2 & 6.22 & 8.05 & 16.25 & 22.07 \\
3 & 5.94 & 8.80 & 15.18 & 20.52 \\
4 & - & 10.11 & 16.43 & 19.38 \\
5 & 5.58 & 9.67 & 14.04 & 20.49 \\
6 & 5.50 & 10.37 & 16.49 & 21.59 \\
\hline Avg & 5.82 & 9.50 & 15.74 & 20.72 \\
Max & 6.22 & 10.37 & 16.49 & 22.07 \\
Min & 5.50 & 8.05 & 14.04 & 19.38 \\
Std Dev & 0.29 & 0.89 & 0.96 & 0.97 \\
\hline
\end{tabular}


Table 8 Results of experiments for truck CAS 20 MAN (FS Zlin)

\begin{tabular}{cccccc}
\hline Initial speed $v_{0}(\mathrm{~km} / \mathrm{h})$ & 30 & 40 & 50 & 60 & 70 \\
\hline Braking time $(\mathrm{s})$ & 2.05 & 2.24 & 2.49 & 2.56 & 3.58 \\
Braking distance $s_{b}(\mathrm{~m})$ & 5.27 & 9.93 & 14.90 & 20.51 & 34.33 \\
Braking deceleration $a_{b}\left(\mathrm{~m} \cdot \mathrm{s}^{-2}\right)$ & 9.67 & 8.02 & 7.97 & 8.10 & 6.24 \\
Coefficient of adhesion $\mu(-)$ & 0.99 & 0.82 & 0.81 & 0.83 & 0.64 \\
\hline
\end{tabular}

Table 9 Results of experiments for truck CAS 20 Renault (FS Zlin)

\begin{tabular}{ccccccc}
\hline Initial speed $v_{0}(\mathrm{~km} / \mathrm{h})$ & 30 & 40 & 50 & 60 & 70 \\
\hline Braking time $(\mathrm{s})$ & 1.65 & 1.84 & 2.40 & 2.67 & 3.39 \\
Braking distance $s_{b}(\mathrm{~m})$ & 5.80 & 10.06 & 14.65 & 7.44 & 32.78 \\
Braking deceleration $a_{b}\left(\mathrm{~m} \cdot \mathrm{s}^{-2}\right)$ & 8.45 & 7.93 & 8.18 & 7.44 & 6.55 \\
Coefficient of adhesion $\mu(-)$ & 0.86 & 0.81 & 0.83 & 0.76 & 0.67 \\
\hline
\end{tabular}

Table 10 Results of experiments for truck CAS 20 SCANIA (FS Marianske Lazne)

\begin{tabular}{cccccc}
\hline Initial speed $v_{0}(\mathrm{~km} / \mathrm{h})$ & 30 & 40 & 50 & 60 & 70 \\
\hline Braking time $(\mathrm{s})$ & 1.33 & 1.83 & 2.37 & 2.97 & 3.68 \\
Braking distance $s_{b}(\mathrm{~m})$ & 5.11 & 9.55 & 16.22 & 23.89 & 33.16 \\
Braking deceleration $a_{b}\left(\mathrm{~m} . \mathrm{s}^{-2}\right)$ & 10.11 & 8.45 & 7.20 & 6.82 & 6.47 \\
Coefficient of adhesion $\mu(-)$ & 1.03 & 0.86 & 0.73 & 0.69 & 0.66 \\
\hline
\end{tabular}

Table 11 Results of experiments for truck CAS 20 TATRA (FS Hlucin)

\begin{tabular}{ccccc}
\hline Initial speed $\mathrm{v}_{0}(\mathrm{~km} / \mathrm{h})$ & 30 & 40 & 50 & 60 \\
\hline Braking time $(\mathrm{s})$ & 1.68 & 2.08 & 2.49 & 3.29 \\
Braking distance $s_{b}(\mathrm{~m})$ & 5.99 & 10.18 & 16.55 & 25.00 \\
Braking deceleration $a_{b}\left(\mathrm{~m} \cdot \mathrm{s}^{-2}\right)$ & 8.10 & 7.80 & 7.07 & 6.43 \\
Coefficient of adhesion $\mu(-)$ & 0.83 & 0.80 & 0.72 & 0.66 \\
\hline
\end{tabular}

Table 12 Results of experiments for truck CAS 24 MAN (FS Hlucin)

\begin{tabular}{ccccc}
\hline Initial speed $v_{0}(\mathrm{~km} / \mathrm{h})$ & 30 & 40 & 50 & 60 \\
\hline Braking time $(\mathrm{s})$ & 1.67 & 2.03 & 2.60 & 2.68 \\
Braking distance $s_{b}(\mathrm{~m})$ & 5.82 & 9.50 & 15.74 & 20.72 \\
Braking deceleration $a_{b}\left(\mathrm{~m}_{\mathrm{s}} \mathrm{s}^{-2}\right)$ & 8.40 & 8.60 & 7.48 & 8.01 \\
Coefficient of adhesion $\mu(-)$ & 0.86 & 0.88 & 0.76 & 0.82 \\
\hline
\end{tabular}

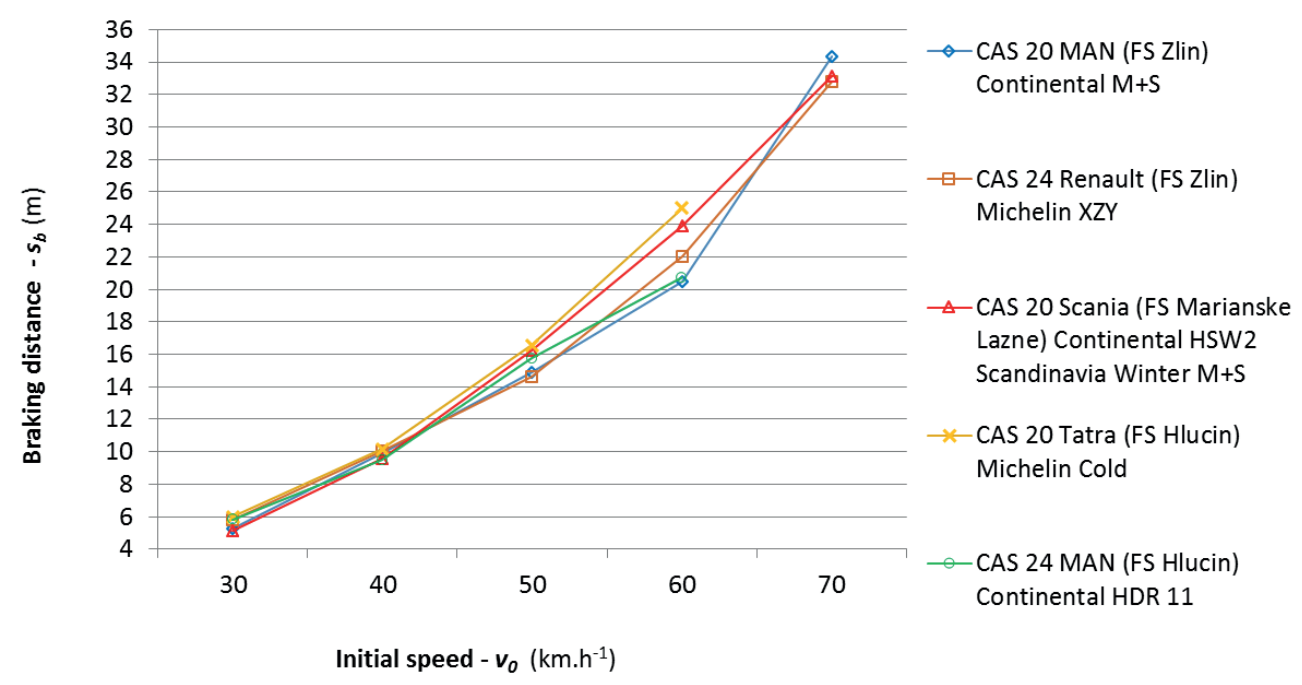

Figure 7 Calculated average values of braking distances of monitored vehicles 


\section{Discussion}

The resulting values may be influenced by several factors when compared to other results of similar experiments. The basic ones, visible at the first glance, are:

- a surface of communication (the coefficient of adhesion),

- tyres (a type, a correct air pressure),

- a vehicle mass,

- a vehicle chassis design (a vehicle technical state),

- a braking system (the function of ABS, ESP systems).

As regards the characteristics of the test road surfaces, the surfaces of the airport runways in Cheb and Slusovice have the less smooth bituminous surface structure than the LIBROS training polygon in Ostrava (built in 2010). That was reflected in the results of the CAS 20 TATRA 815-2 truck which, at an initial speed $60 \mathrm{~km} \cdot \mathrm{h}^{-1}$, had the longest average braking distance of $25.0 \mathrm{~m}$. The CAS 24 MAN (FS Hlucin) vehicle of the same mass was tested on the same track, on the same day and under similar climatic conditions. That vehicle was able to brake at the same initial speed on an average braking distance of $20.72 \mathrm{~m}$. The difference in the braking distances, therefore, was not inflicted by the quality of the communication surface. The equally heavy (18t) truck CAS 20 SCANIA had an average braking distance of $23.89 \mathrm{~m}$ reached on the runway at an initial speed $60 \mathrm{~km} \cdot \mathrm{h}^{-1}$.

The impact of the type of tyres is not clear from the results of the testing. Each vehicle was fitted with a different type of tyre on the front and rear axles. A summary of the tyre types used at each vehicle is given in Tables 13 and 14, including their essential characteristics and intended use (according to the manufacturer). Differences in lengths of the braking distances are noticeable at speeds $60 \mathrm{~km} \cdot \mathrm{h}^{-1}$ and higher.

A very approximate comparison can be given to the measurement and testing at the FRS of the South Moravia Region which took place at the Autodrom Brno, a. s. on November 26, 2018. There, measurements were made on 6 water tenders vehicles based on TATRA 815-2 $4 \times 4$ and SCANIA $4 \times 4$ chassis. There were different tires on each vehicle. Test runs of vehicles with a full water tank, on a dry bituminous surface, were measured at initial speeds of 40 and $50 \mathrm{~km} \cdot \mathrm{h}^{-1}$. The accuracy of the measurements to decimetres was consistent with using the metal tape meter. According to the measurements provided, the best tyre was Continental HSW2 Scandinavia Winter $\mathrm{M}+\mathrm{S}$ with a braking distance up to $7 \mathrm{~m}$ at the speed $40 \mathrm{~km} \cdot \mathrm{h}^{-1}$, and up to $12 \mathrm{~m}$ at the speed $50 \mathrm{~km} \cdot \mathrm{h}^{-1}$. The worst results were obtained for the Continental HSC1 tyres with a stopping distance up to $9.1 \mathrm{~m}$ at the speed $40 \mathrm{~km} \cdot \mathrm{h}^{-1}$, and up to $14.5 \mathrm{~m}$ at the speed $50 \mathrm{~km} \cdot \mathrm{h}^{-1}$.

Such differences did not result from these measurements. The predicted best tyre Continental HSW2 was fitted on a SCANIA vehicle which, at 60 $\mathrm{km} \cdot \mathrm{h}^{-1}$, had an average braking distance of $23.89 \mathrm{~m}$. Hypothetically, the worst tyres Continental HSC1 fitted on a CAS 20 MAN vehicle (FS Zlin) during the tests had an average stopping distance of $20.51 \mathrm{~m}$ at $60 \mathrm{~km} \cdot \mathrm{h}^{-1}$. Here, the difference in weight of these vehicles (18 versus 14 tonnes) had an effect, as well as the fact that the winter tyre has a greater braking distance at air temperatures over $0{ }^{\circ} \mathrm{C}$.

The impact of the weight of the vehicle is also not clear-cut with respect to the conducted experiments. This fact can be the best demonstrated by results for an initial speed of $60 \mathrm{~km} \cdot \mathrm{h}^{-1}$, which were presented in the text above. TATRA and SCANIA as the heaviest

Table 13 Types of tyres on the front axle and their characteristics

\begin{tabular}{llll}
\hline Vehicle & Dislocation & Tyre on the front axle & Characteristics \\
\hline CAS 20 MAN TGM & FS Zlin & Continental HSC1 M+S & Construction, all-season, steer. \\
CAS 24 Renault Midlum & FS Zlin & Michelin XZY 10 & Mixed transport, all-season, steer / drive. \\
CAS 20 Scania & FS Marianske & Continental HSW2 Scandinavia & Resistance on snow surface, winter, \\
steer. & Winter M+S & Mixed transport, all-season, steer. \\
CAS 20 TATRA T815-2 & FS Hlucin & Michelin Cold & Regional transport, all-season, drive. \\
\hline
\end{tabular}

Table 14 Types of tyres on the rear axle and their characteristics

\begin{tabular}{llll}
\hline Vehicle & Dislocation & Tyre on the rear axle & Properties \\
\hline CAS 20 MAN TGM & FS Zlin & Continental HDC1 M+S & Construction, all-season, drive. \\
CAS 24 Renault Midlum & FS Zlin & Bridgestone M 716 10 & High-way transport, all-season, drive. \\
CAS 20 Scania & $\begin{array}{l}\text { FS Marianske } \\
\text { Lazne }\end{array}$ & Continental HDC1 M+S & Construction, all-season, drive. \\
CAS 20 TATRA T815-2 & FS Hlucin & Barum Road Drive & $\begin{array}{l}\text { Regional transport, winter, drive } \\
\text { Regional and high-way transport, all- } \\
\text { CAS 24 MAN TGM }\end{array}$ \\
\hline
\end{tabular}




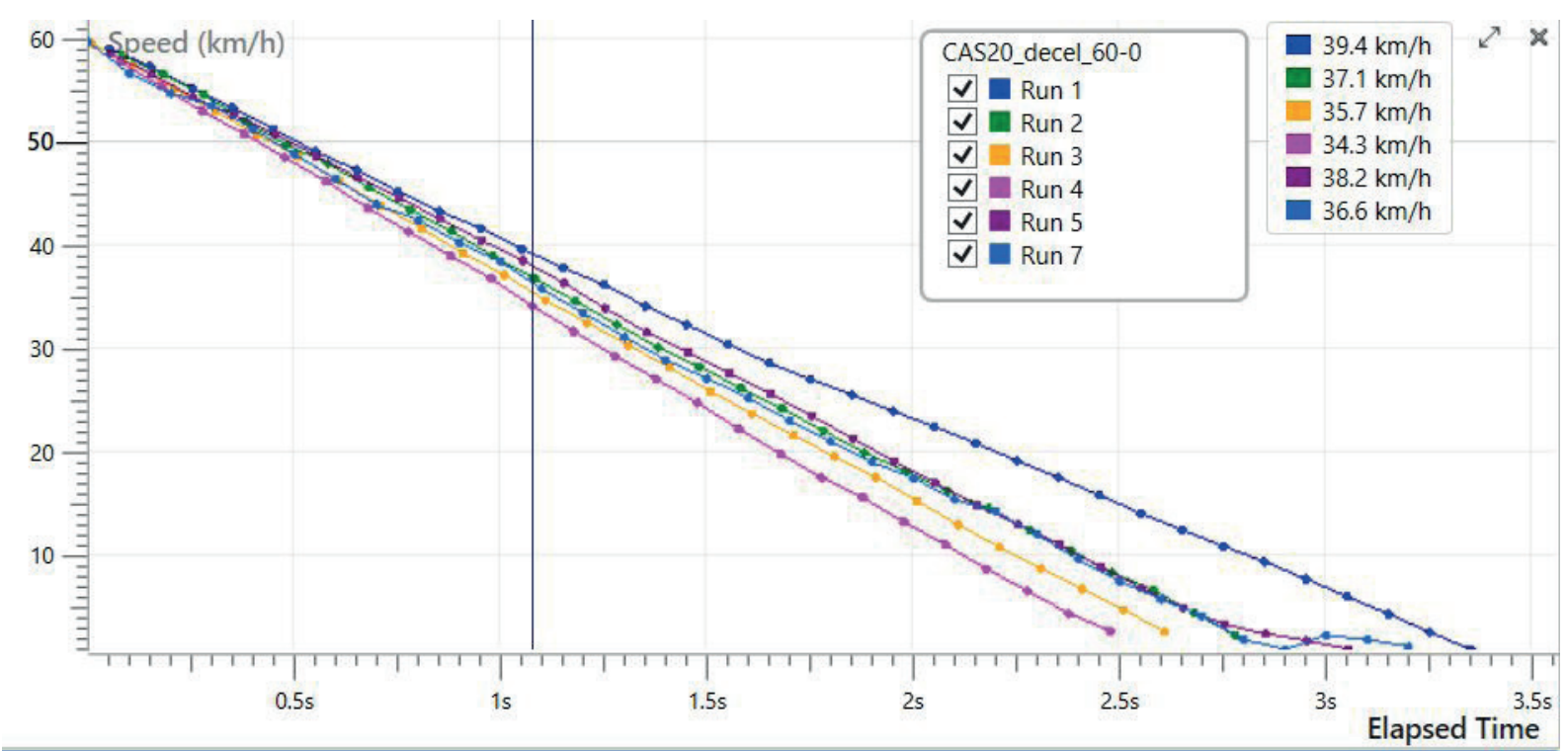

Figure 8 Progress of the braking speed change of the vehicle SCANIA in tests

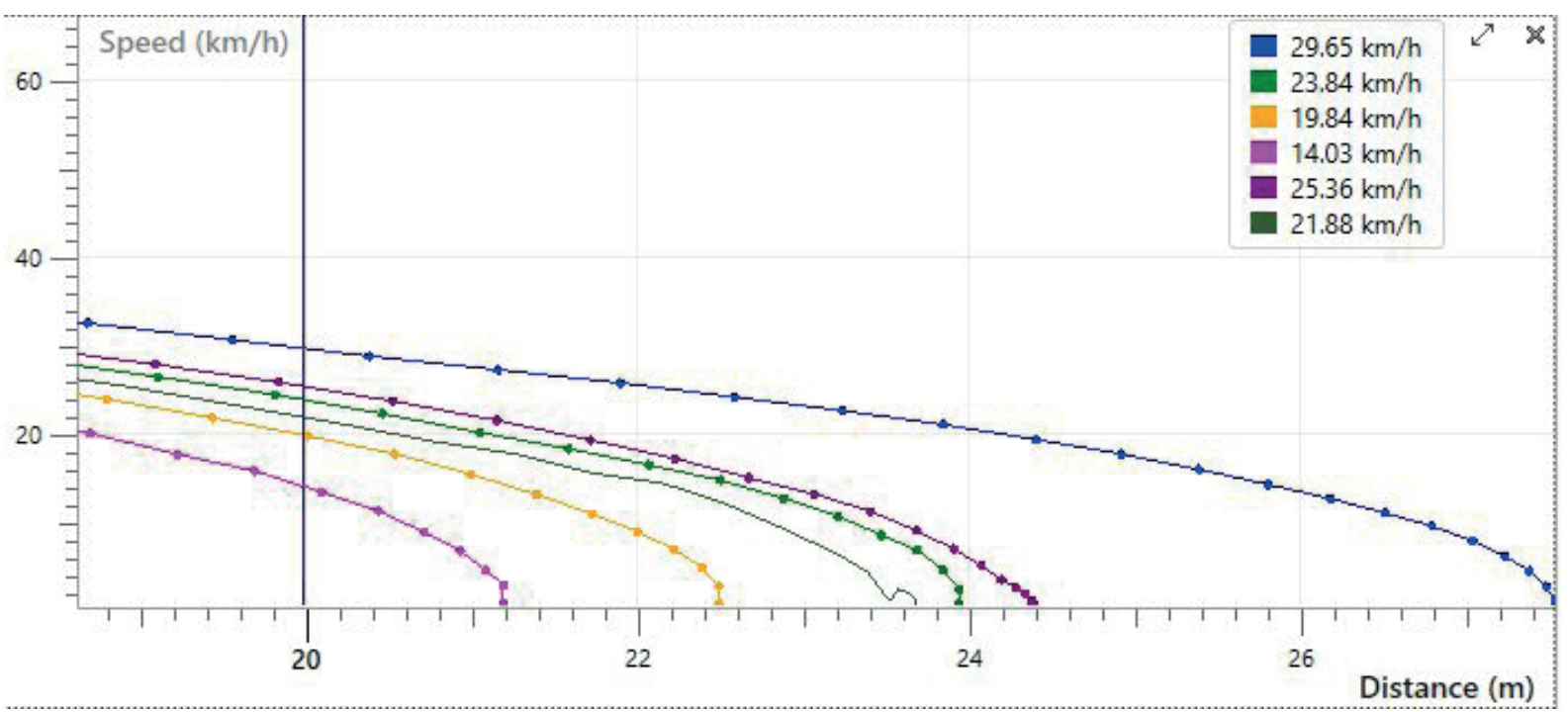

Figure 9 Detail of the SCANIA vehicle braking progress in tests

vehicles (of 18 tonnes) have the longest average braking distance. On the contrary, the CAS 24 MAN (FS Hlucin) of the same weight $18 \mathrm{t}$ has the second shortest braking distance of $20.7 \mathrm{~m}$. The CAS 20 MAN (FS Zlin) with the weight of $16.5 \mathrm{t}$ reached the shortest braking distance of $20.51 \mathrm{~m}$ on average. The lightest CAS 20 Renault vehicle (of $14.5 \mathrm{t}$ ) had an average stopping distance of $22.02 \mathrm{~m}$.

Regarding the effect of the type of vehicle chassis design, only the water tender CAS 20 TATRA 815-2 has a chassis built on the so-called supporting backbone tube to which swinging semi-axles are attached. The other vehicles tested have a rigid frame with a shape memory. As a single representative of a different design has been tested here, its negative effect on the length of the stopping distance cannot be demonstrated. The technical condition of all the vehicles tested was $100 \%$, as prescribed by the FRS CR internal rules.

The braking system of the majority of vehicles tested is built on drum brakes. The exception is the vehicle
CAS 24 Renault (FS Zlin), which has disc brakes on both axles. However, their advantage in achieving the best stopping distance only began to be felt at an initial speed of $70 \mathrm{~km} . \mathrm{h}^{-1}$. All the vehicles have an ABS system. Only the SCANIA vehicle has an ASR system. The function of these systems on the dry surface was not observed, nor measurable by the used telemetry, which operates at the frequency $10 \mathrm{~Hz}$. To illustrate that, a graphic record of the SCANIA vehicle braking progress is shown in Figure 8 , obtained after evaluating the tests at the initial speed of $60 \mathrm{~km} \cdot \mathrm{h}^{-1}$.

The only observable change in the braking process is shown in Figure 9. There is shown a graphical relation of the speed change and stopping distance, on the graph. For the test run No. 7, there was a change in the expected braking pattern on the $21.72 \mathrm{~m}$ braking distance travelled (indicated by a blue vertical cursor). However, it can only be speculated about their causes with the $10 \mathrm{~Hz}$ frequency of recordings. 
Table 15 Average braking distances of tested vehicles

\begin{tabular}{ccccccc}
\hline $\mathrm{v}_{0}\left(\mathrm{~km} \cdot \mathrm{h}^{-1}\right)$ & 30 & 40 & 50 & 60 & 70 & Vehicle (dislocation) \\
\hline & 5.27 & 9.93 & 14.90 & $20.51^{*}$ & 34.33 & CAS 20 MAN (FS Zlin) \\
& 5.80 & 10.06 & $14.65^{*}$ & 22.02 & 32.78 & CAS 24 Renault (FS Zlin) \\
$\mathrm{s}_{\mathrm{b}}(\mathrm{m})$ & $5.11^{*}$ & 9.55 & 16.22 & 23.89 & 33.16 & CAS 20 Scania (FS Marianske Lazne) \\
& 5.99 & 10.18 & 16.55 & 25.00 & & CAS 20 Tatra (FS Hlucin) \\
& 5.82 & $9.50^{*}$ & 15.74 & 20.72 & & CAS 24 MAN (FS Hlucin) \\
\hline
\end{tabular}

Another essential factor that is not immediately visible is the gradual warming of the braking system during the tests. The state in which this factor starts to affect the braking distance is different for each vehicle. In performed tests, it started to show up after about 15 braking cycles, up to an initial speed of $50 \mathrm{~km} . \mathrm{h}^{-1}$. It was fully apparent when braking from higher initial speeds of 60 and $70 \mathrm{~km} \cdot \mathrm{h}^{-1}$. In the above experiments, the temperature of the braking system was not measured, nor was it corrected by driving the vehicle around to cool the braking system to an acceptable operating temperature.

In parallel to these experiments, the precise measurements were carried out during the testing of the driving characteristics of TATRA 815-2 4x4, SCANIA P440 4x4, Mercedes-Benz Econic 4x2 and TATRA 815-7 6x6 vehicles, as a part of the project under consideration. In 2019 and 2020, each vehicle underwent twice a one-week series of repeated measurements and test runs on the LIBROS polygon in Ostrava. The following devices formed the basis of the measurement assembly - VBOX Dual GPS telemetry (manufacturer RaceLogic Ltd., England) operating with a $20 \mathrm{~Hz}$ recording frequency and serving to an accurately scan of the driving dynamics without the impact of the weather conditions and AIM EVOS for recording and scanning of the driving dynamics together with scanning number of sensor signals (brake temperature, air temperature in sub-runs).

Prior to the beginning of the experiments, brake drums or a disc on the right front wheel of all the vehicles were modified. A hole was drilled and a thermocouple installed to measure the temperature. Detailed cumulative results of these measurements will be published shortly by colleagues - co-investigators of the project led by Martin Fusek (Faculty of Mechanical Engineering, VSB - TU Ostrava) and Miroslav Vaculik (Faculty of Materials Science and Technology, VSB - TU Ostrava). However, to tell in short, the two temperature states of the terminal action elements of the braking system are:

- $t_{\text {opt }}=95$ to $165{ }^{\circ} \mathrm{C}$ - the working temperature of the brakes, when they begin to perform their function fully and the effectiveness of the brakes is not affected due to their temperature,

- $t_{k}=$ above $200{ }^{\circ} \mathrm{C}$ - the critical temperature at which, beyond this limit, the brakes fail to perform properly - the braking distance of the vehicle lengthens noticeably.
During these experiments, the overheating of the brakes was always corrected by driving the vehicle around the circuit to cool the braking system to an acceptable operating temperature below $200^{\circ} \mathrm{C}$.

\section{Conclusions}

A summary of the measurement results of the braking distances and the calculated average values (see Tables 3 to 7 and Figure 7) are given in Table 15. The best results are highlighted by sign * there. It is clear that lighter vehicles (Renault and MAN from FS Zlin) can brake better with increasing initial speed. The heavy vehicle (TATRA) had the longest braking distance values in all tests performed.

After evaluating the above test results and the knowledge acquired, within the project under consideration (see Acknowledgments) it was decided to narrow the selection to one water tender vehicle and three sets of corresponding tyres and further test their driving performance. A CAS 20/4000/240 vehicle was selected on the Scania P440 CB 4x4 chassis section. The following types of tyres from manufacturer Continental AG were tested as part of the verification:

- Continental HSW2 (front axle), HDW2 (rear axle), Scandinavia Winter $\mathrm{M}+\mathrm{S}$,

- Continental Conti Cross Trac HS3 (front axle), HD3 (rear axle), $\mathrm{M}+\mathrm{S}$,

- Continental Conti Hybrid HS3 (front axle), HD3 (rear axle), $\mathrm{M}+\mathrm{S}$.

Verification of the performance of the tyres was carried out from June 29 to July 1, 2020. The results are currently being evaluated. They will then be factored into the design of the methodological procedure for verifying the technical parameters of tires for the firefighting water tenders.

\section{Acknowledgments}

This paper was created within the framework of the security research, based on a contract for provision of targeted support for the solution of a research, development and innovation project entitled "Emergency fire-fighting vehicles' safe driving for intervention” Id. No. VH20182021035 signed by the contracting parties Czech Republic - Ministry of Interior and VSB - Technical University of Ostrava. 


\section{References}

[1] SUDRYCHOVA, I., KUCZAJ, J., JANOSIK, L., POLEDNAK, P., JANOSIKOVA, I. Firefighting vehicles' braking distance metering. Communications - Scientific Letters of the University of Zilina [online]. 2019, 21(3), p. 85-91. ISSN 1335-4205, eISSN 2585-7878. Available from: https://doi.org/10.26552/com.C.2019.3.85-91

[2] JANOSIK, L., JANOSIKOVA, I., COCHLAR, M., JEMELIK, S. Economic aspects of firefighting vehicles safe driving within EU civil protection. In: 4th International Conference on European Integration 2018: ICEI 2018: proceedings. 2018. ISBN 978-80-248-4169-4, ISSN 2571-029X, p. 556-565.

[3] JANOSIK, L., JANOSIKOVA, I., COCHLAR, M., POLEDNAK, P., SUDRYCHOVA, I. Economic consequences of firefighting trucks risky emergency driving within EU civil protection. In: 5th International Conference on European Integration 2020: ICEI 2020: proceedings [online]. 2020. ISBN 978-80-248-4455-8, eISBN 978-80-2484456-5, ISSN 2571-029X, p. 330-337. Available from: https://doi.org/10.31490/9788024844565

[4] VBOX Motorsport. Products - Racelogic Ltd. [online] [accessed 2020-05-07]. Available from: https://www. vboxmotorsport.co.uk/index.php/en/products/performance-meters/performancebox

[5] VLK, F. Working on dynamics of motor vehicles (in Czech). Brno: Prof. Ing. Frantisek Vlk, DrSc., publishing, 2001. ISBN 80-238-6574-9.

[6] VLK, F. Dynamics of motor vehicles (in Czech). Brno: Prof. Ing. Frantisek Vlk, DrSc. publishing, 2003. ISBN 80-239 -0024-2.

[7] MAPY.CZ - Seznam.cz a.s. [online] [accessed 2020-05-07]. Available from: https://mapy.cz/ 